\title{
Fatigue performance of wood frame roof-to-wall connections with elastomeric adhesives under uplift cyclic loading
}

\author{
Bilal Alhawamdeh ${ }^{\mathrm{a},{ }^{*}}$, Xiaoyun Shao ${ }^{\mathrm{b}}$ \\ ${ }^{a}$ Ph.D., Research Assoc at Bronco Construction Research Center, Kalamazoo, MI, Email: \\ byz6845@wmich.edu \\ ${ }^{b}$ Assoc. Professor at Western Michigan Univ, Kalamazoo, MI, Email: xiaoyun.shao@wmich.edu
}

\begin{abstract}
:
Roof-to-wall-connection (RTWC) is critical in the loading path of wood-frame residential buildings, whose fatigue performance under varying wind loading is investigated in this study. To get an insight on the wind induced fatigue behavior at low to moderate hourly mean wind speeds and to demonstrate the effects of adhesives on the fatigue performance of RTWC, two types of fatigue experiments, namely the constant and the varying amplitude loading tests, were conducted on three RTWC configurations with and without elastomeric construction adhesives. Based on the constant amplitude loading test results, fatigue life prediction models were developed, and the reduction in the static load capacity due to cyclic loadings were estimated. Adhesives are shown to increase the endurance limit of the RTWCs, which is desirable to enhance the life-cycle performance of wood buildings. The varying amplitude loading test results indicate that buildings in non-hurricane regions are vulnerable to fatigue damage at a low-level mean wind speed. It may induce loadings above the endurance limit of the RTWCs. On the other hand, the linear Miner's cumulative fatigue damage model can be reasonably used to predict fatigue damage of the RTWCs when subject to multi-amplitude wind loadings. The testing results presented herein provide essential data on the hysteresis behavior and failure modes of RTWCs to facilitate future implementation of adhesives in wood constructions.
\end{abstract}

Keywords: Wind loads; Fatigue analysis; Roof-to-wall connection; Elastomeric adhesives

\section{INSTRODUCTION}

Roof-to-wall connections (RTWCs) and roof sheathing in residential wood-frame buildings having significant influences on the roof performance under wind loads. The critical role of these connections was also revealed from many post-hurricane/storm damage surveys (e.g., [1]-[3]). Not only will roof failure endanger occupants of the houses, but it also led to water intrusion, resulting in significant subsequent damage to household items inside, such as furniture and appliances.

An experiment conducted by the Insurance for Business \& Home Safety (IBHS) on a full-scale house under the impact of open wind turbines shows that the roof failure initiated at the rafter- totop plate connections due to inadequacy in resisting and transferring loads [4]. Toenails are the most common fasteners used in RTWC in North America, and significant roof structure failures were due to the failure of these conventional connections, among which many were observed at wind speeds below the design level [5]-[7]. The underperformance of the roof connection can mainly attribute to the improper selection and application of construction materials (i.e., fasteners, wood framing, and sheathing) or strength degradation due to aging and long-term service within the intended life span [8]. 
The capacity of toenail connections to uplift loads has been the subject of many studies. For example, [9]-[17] examined various connection strengthening approaches, such as commercial metal straps and construction adhesives. Research on the effect of adhesive materials to wood construction has gained attention. Generally, better performance of structural members (i.e., roof connection, sheathing) under natural hazardous loading conditions was observed when adhesive materials were adopted in the construction [18]. Monotonic loading tests of RTWC specimens demonstrated that increased uplift resistances were achieved with the application of the elastomeric adhesives, which may provide an affordable, efficient, and nonintrusive solution for roof connections in high wind areas.

One way to evaluate the connection's capacity under long-duration wind load might be through low cyclic fatigue experiments, which were adopted in several studies to investigate the fatigue damage of metal roof claddings. Fatigue testing program of mechanical fixation elements of roofed low-rise structures was developed based on the design wind pressure [19], during which wind cycles of certain wind speed was estimated considering the cumulative probability distribution of the 50-year return period. Fatigue performance of light gauge roofing was evaluated based on the cycles to fatigue failure versus loading levels, which were determined using the wind loading spectrum of a design wind event [20]. Another procedure for estimating the wind-induced fatigue damage of roof claddings was developed in [21], [22], during which a rainflow count method was employed to determine the fatigue loading from a measured cyclone wind load history based on a wind tunnel testing of a model house. The S-N curve, where $\mathrm{S}$ represents the stress amplitude, and $\mathrm{N}$ is the number of cycles until failure, was used to estimate the fatigue damage in conjunction with Miner's rule.

It shall be pointed out that damage accumulation mechanism in low cycle fatigue for metal roof claddings is different from those of nailed connections in wood-framed buildings [23]. Understanding whether the fluctuating wind loading of longer duration and relatively lower amplitude will induce fatigue failure is critical for wind resistance performance evaluation of RTWCs, especially, in non-hurricane regions where toenails still dominate the wood frame constructions. These regions are exposed to winds with low to moderate speeds all year-long, where the damage is not expected due to overloading [24]. Therefore, the objectives of this study are twofold: (i) to estimate the wind-induced fatigue damage of standard toenailed RTWCs (ii) to evaluate wind-induced fatigue mitigation performance of the proposed strengthening method using elastomeric adhesives.

\section{METHODOLOGY}

The flowchart shown in Figure 1 illustrates the fatigue preformation evaluation of the roof connections employing both the constant and the varying amplitude loading tests. On the left, steps to develop the $S-N$ curve are demonstrated, including the determination of the endurance limit based on the constant amplitude loading tests. The mathematical relationship between the applied load and fatigue life, known as the fatigue load-life model, is then established based on the regression analysis. On the right, the rainflow count method is used to determine the wind-induced cyclic load (i.e., the varying amplitude loading protocol) from the wind-force time history. Fatigue damage of the test specimen of each configuration under the varying amplitude loadings is quantified using the $D I$ defined in Eq. 1 , where $N_{f j}$ is estimated using the fatigue load-life model for the $F_{a r}$ values resulted from the rainflow cyclic counting analysis, while the number of cycles applied $\left(N_{j}\right)$ are directly obtained from the varying amplitude loading tests. The hysteresis curves 
and displacement behavior are analyzed to provide reasonable explanations for the connections' fatigue performance and failure modes observed from both tests.

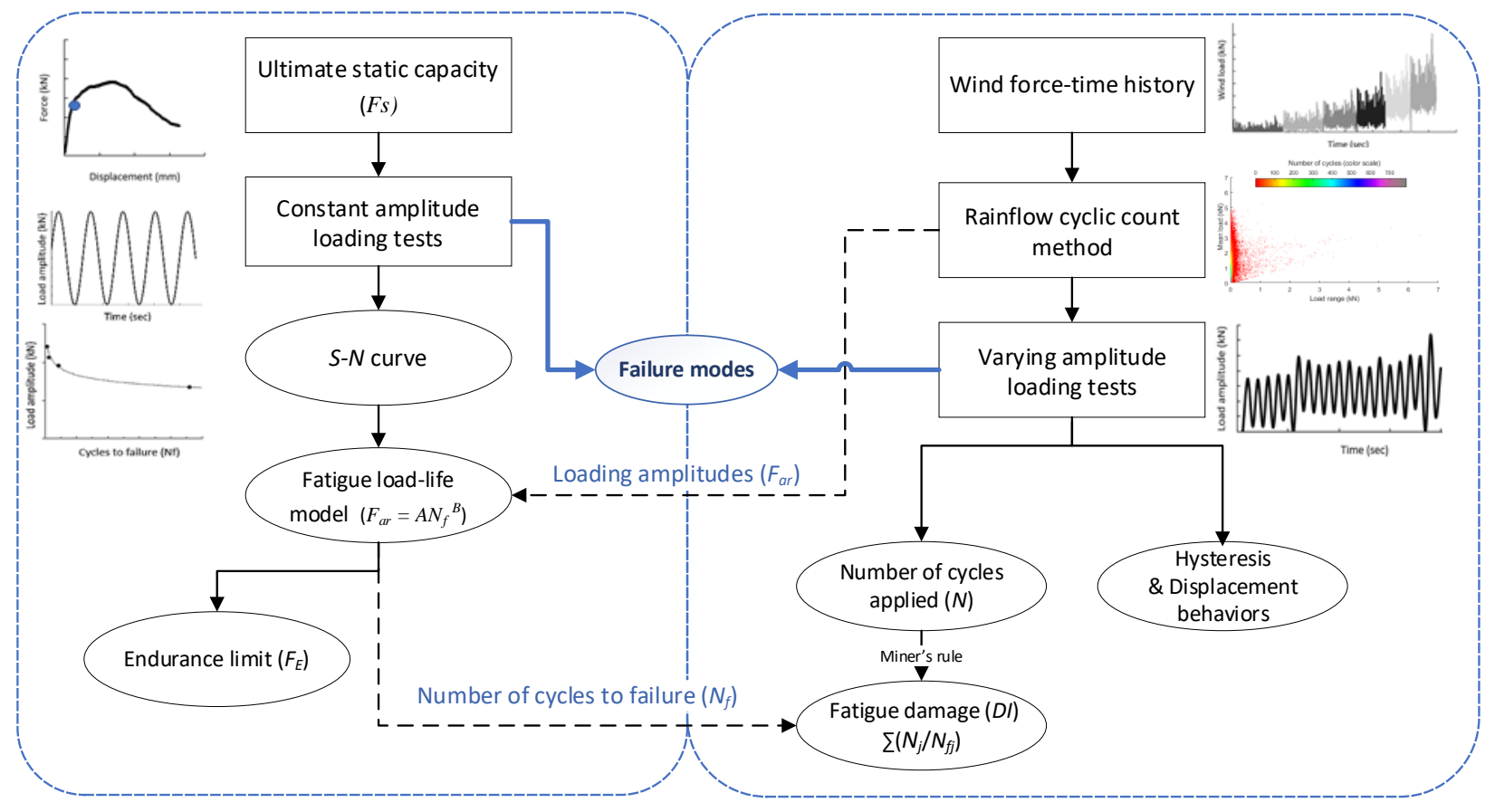

Figure 1. Fatigue performance evaluation using constant and varying amplitude loading tests

In this study, the cumulative fatigue damage index $(D I)$ is defined based on Miner's model to quantify the specimen's fatigue damage under multiple load amplitudes:

$$
D I=\sum_{j=1}^{m} D_{j}=\sum_{j=1}^{m} \frac{N_{j}}{N_{f j}}
$$

where $D_{j}$ is the proportional fatigue damage of the $j^{\text {th }}$ loading amplitude $(1 \leq \mathrm{j} \leq \mathrm{m})$, and $m$ is the total number of loading amplitudes. $N_{j}$ is the number of cycles applied at the $j^{\text {th }}$ loading amplitude, and $N_{f j}$ is the number of cycles to failure under the constant loading of the $j^{\text {th }}$ amplitude. According to Miner's rule in Eq. 1, fatigue failure is expected when DI reaches unity, that is when $100 \%$ of life is exhausted [25].

\section{REFERENCES}

[1] J. W. van de Lindt, A. Graettinger, R. Gupta, T. Skaggs, S. Pryor, and K. J. Fridley, "Performance of Wood-Frame Structures during Hurricane Katrina," J. Perform. Constr. Facil., vol. 21, no. 2, pp. 108-116, Apr. 2007, doi: 10.1061/(ASCE)08873828(2007)21:2(108).

[2] M. O. Amini and J. W. van de Lindt, "Quantitative Insight into Rational Tornado Design Wind Speeds for Residential Wood-Frame Structures Using Fragility Approach,” J. Struct. Eng., vol. 140, no. 7, p. 04014033, 2014, doi: 10.1061/(ASCE)ST.1943-541X.0000914.

[3] M. J. Morrison, G. A. Kopp, E. Gavanski, C. Miller, and A. Ashton, "Assessment of damage to residential construction from the tornadoes in Vaughan, Ontario, on 20 August 2009," Can. J. Civ. Eng., vol. 41, no. 6, pp. 550-558, Jun. 2014, doi: 10.1139/cjce-2013-0570.

[4] "Insurance Institute for Business and Home Safety." https://disastersafety.org/ (accessed Nov. 02, 2017).

[5] FEMA 548, "Summary Report on Building Performance Hurricane Katrina 2005,” 2006. 
[Online]. Available: https://www.fema.gov/media-library/assets/documents/1054.

[6] FEMA, "Report Hurricane Charley in Florida Observations, Recommendations, and Technical Guidance," 2005.

[7] FEMA, "Wind retrofit guide for residential buildings," Department of Homeland Security, Washington, D.C. : U.S., 2010.

[8] D. Henderson, C. Williams, E. Gavanski, and G. A. Kopp, "Failure mechanisms of roof sheathing under fluctuating wind loads," J. Wind Eng. Ind. Aerodyn., vol. 114, pp. 27-37, 2013, doi: 10.1016/j.jweia.2013.01.002.

[9] T. D. Reed, D. V. Rosowsky, and S. D. Schiff, "Uplift Capacity of Light-Frame Rafter to Top Plate Connections," J. Archit. Eng., vol. 3, no. 4, pp. 156-163, Dec. 1997, doi: 10.1061/(ASCE)1076-0431(1997)3:4(156).

[10] W. C. Edmonson, S. D. Schiff, and B. G. Nielson, "Behavior of Light-Framed Wood Roofto-Wall Connectors Using Aged Lumber and Multiple Connection Mechanisms," J. Perform. Constr. Facil., vol. 26, no. 1, pp. 26-37, Feb. 2012, doi: 10.1061/(ASCE)CF.19435509.0000201.

[11] L. Canfield, S. Niu, and H. Liu, "UPLIFT RESISTANCE OF VARIOUS RAFTER-WALL CONNECTIONS," For. Prod. J., vol. 41, no. 7-8, pp. 27-34, 1991.

[12] J. Cheng, "Testing and analysis of the toe-nailed connection in the residential roof-to-wall system," For. Prod. J., vol. 54, no. 4, pp. 58-65, 2004.

[13] H. W. Conner, D. S. Gromala, and D. W. Burgess, "Roof Connections in Houses: Key to Wind Resistance," J. Struct. Eng., vol. 113, no. 12, pp. 2459-2474, Dec. 1987, doi: 10.1061/(ASCE)0733-9445(1987)113:12(2459).

[14] R. Michael and F. Sadek, "Experimental testing of roof to wall connections in wood frame houses," Gaithersburg, Md. : U.S. Department of Commerce, Technology Administration, National Institute of Standards and Technology, 2003.

[15] M. a. Turner, R. H. Plaut, D. a. Dillard, J. R. Loferski, and R. Caudill, "Tests of Adhesives to Augment Nails in Wind Uplift Resistance of Roofs," J. Struct. Eng., vol. 135, no. 1, pp. 88-93, Jan. 2009, doi: 10.1061/(ASCE)0733-9445(2009)135:1(88).

[16] D. J. Alldredge, J. A. Gilbert, H. A. Toutanji, T. Lavin, and M. S. Balasubramanyam, "Uplift Capacity of Polyurea-Coated Light-Frame Rafter to Top Plate Connections," J. Mater. Civ. Eng., vol. 24, no. 9, pp. 1201-1210, Sep. 2012, doi: 10.1061/(ASCE)MT.19435533.0000492.

[17] C. Canbek, A. Mirmiran, A. G. Chowdhury, and N. Suksawang, "Development of FiberReinforced Polymer Roof-to-Wall Connection,” J. Compos. Constr., vol. 15, no. 4, pp. 644652, 2011, doi: 10.1061/(asce)cc.1943-5614.0000194.

[18] B. Alhawamdeh and X. Shao, "Uplift Capacity of Light-Frame Rafter to Top Plates Connections Applied with Elastomeric Construction Adhesives," J. Mater. Civ. Eng., vol. 32, no. 5, p. 04020078, May 2020, doi: 10.1061/(ASCE)MT.1943-5533.0003152.

[19] H. J. Gerhardt and C. Kramer, "Wind induced loading cycle and fatigue testing of lightweight roofing fixations," J. Wind Eng. Ind. Aerodyn., vol. 23, pp. 237-247, Jan. 1986, doi: 10.1016/0167-6105(86)90045-0.

[20] M. Mahendran, "Fatigue behaviour of corrugated roofing under cyclic wind loading," Trans. Inst. Eng. Aust. Civ. Eng., vol. CE32, no. 4, pp. 219-226, 1990.

[21] E. D. Jancauskas, M. Mahendran, and G. R. Walker, "Computer simulation of the fatigue behaviour of roof cladding during the passage of a tropical cyclone," J. Wind Eng. Ind. Aerodyn., vol. 51, no. 2, pp. 215-227, 1994, doi: 10.1016/0167-6105(94)90005-1.

[22] Y. L. Xu, "Fatigue damage estimation of metal roof cladding subject to wind loading," $J$. Wind Eng. Ind. Aerodyn., vol. 72, no. 1-3, pp. 379-388, 1997, doi: 10.1016/S01676105(97)00254-7.

[23] T. K. Guha and G. A. Kopp, "Storm duration effects on roof-to-wall-connection failures of a residential, wood-frame, gable roof," J. Wind Eng. Ind. Aerodyn., vol. 133, 2014, doi: 10.1016/j.jweia.2014.08.005.

[24] A. Tom Smith, "Wind Safety of the Building Envelope | WBDG - Whole Building Design Guide," 2017. https://www.wbdg.org/resources/wind-safety-building-envelope (accessed 
May 09, 2020).

[25] M. A. . Miner, "Cumulative damage in fatigue," J. Appled Mech., vol. 12, no. 3, pp. 159164, 1945. 